Egypt. J. of Nutrition and Health Vol. 14 No. 2 July (2019)

\title{
Anti-ulcer Activity of Avocado Juice and Kiwi Juice on Indomethacin Induced Gastric Ulcer in Rats
}

\author{
Amira L. Abd Allah \\ Nutrition and Food Science Dept., Faculty of Home Economics, Al- Azhar University
}

\begin{abstract}
Over past decades, physicians have recommended dietary adjustments, aimed at preventing or treating symptoms of peptic ulcer, as a diet that moderates the risk of stomach ulceration. This study aims to investigate the effect and mechanism of consumption of avocado (Persea americana Mill) juice and kiwi (Actinidia deliciosa) juice to alleviate peptic ulcer in rats. Thirty-six male albino rats $(185 \pm 10 \mathrm{~g})$, were used and divided into 6 equal groups, one was kept as a (-ve) control group, while the other groups were received daily oral dose of indomethacin $(25 \mathrm{mg} / \mathrm{kg}$ b.Wt.) once daily for 21 days. One group received Indo only (+ve control group), while the other groups given orally $(1.5,3 \mathrm{ml}$ per day) of each juice for 21 days plus Indo. Peptic ulcer index, preventive index, and acidity of gastric juice were assessed. Nitric oxide (NO), malondialdehyde (MDA) and glutathione (GSH) were measured in gastric tissue, as well as histopathological changes in the gastric mucosa. Treatment with avocado juice and kiwi juice resulted in amelioration of the gastric histological lesions induced by Indo. Moreover, fresh juices of avocado and kiwi significantly modulated biochemical marker of oxidative/nitrosative stress markers; malondialdehyde (MDA), and nitric oxide (NO) and antioxidant enzymes as glutathione (GSH), which were significantly disrupted in animal treated with Indo alone. According to this study, the fresh juices of avocado and kiwi could protect against peptic ulcer and its other side effects. This may be due to the high content of phenolic and flavonoid compounds in these juices.
\end{abstract}

Keywords: Peptic ulcer - Indomethacin - Avocado - kiwi - Nitric oxide - Glutathione

\section{Introduction}

Peptic ulcer happens as an acid-stimulated lesion of the digestive tract, usually situated in the proximal duodenum or in the stomach. It is distinguished by bared mucosa with a defect spreading into the submucosa or muscularis propria (Narayanan et al., 2018). The approximate rate of peptic ulcer disease is $5-10 \%$ in the global population (Lanas and Chan 2017). The development of peptic ulcer relies on the existence of low gastric liquid $\mathrm{pH}$ and the weakening in mucosal defenses. The nonsteroidal anti-inflammatorc drugs (NSAIDs), as well as, the infection resulted from Helicobacter pylori (H. pylori) are the two main factors disturbing the mucosal defiance to damage (Kuna et al., 2019). Moreover, the risk of gastric ulcer complications is raised four times in NSAIDs users (Lanas et al., 2015).

NSAID is a class of analgesics that contain traditional selective and nonselective cyclooxygenase-2 inhibitors that hinder the biosynthesis of thromboxane and prostaglandins (Nalamachu and Wortmann, 2014). Globally, NSAIDs are a group of the most frequently prescribed drugs for their anti-inflammatory and analgesic properties (Scheiman et al., 2006; Targownik et al., 2008). Day by day, the uses of NSAIDs are increasing and still broadly used due to their low cost (Seth, 2005). In spite of their efficacy, NSAIDs are used as one of the key factors causing peptic ulcer diseases (Wallace and Vong, 2008). Currently, the use of NSAIDs estimated by about $25 \%$ of gastric 
ulcer cases (Lanas et al., 2015). Long-term usage of NSAIDs was associated with serious adverse influences such as gastrointestinal bleeding, ulcer puncture, and symptomatic gastric ulcer disease (Targownik et al., 2008).

Indomethacin (Indo) also is one of the non-steroidal anti-inflammatory drugs with strong antipyretic, anti-inflammatory and analgesic activity that has been efficiently used in the relieving mildto-moderate pains (Nalamachu and Wortmann, 2014). Recently, preventing or curing peptic ulcers is one of the most critical challenges in meeting the medicine industry in the field (Darbar, 2010). The commercially existing synthetic anti-ulcer drugs, such as anti-acids, histamine $\mathrm{H}_{2}$ receptor antagonists, in addition to proton pump inhibitors, are often costly, have numerous side effects, moreover, they don't prevent ulcer recurrence (Chan, 2006).

Therefore, there is a critical need to find out plants with medical properties that help in preventing and treating gastric ulcer (Rivera et al., 2013), as well for many reasons such as their low cost, improving the life quality and for pain-relieving (Garlord and Crotty, 2002). It is estimated that approximately $80 \%$ of the population has used herbs or natural medicines worldwide with around a $15 \%$ increase rate in the developing countries (Robinson and Zhang, 2011). Previous studies as indicated by Ryan (2005) have revealed that many medicinal herbs and plants used in conventional medicine for treating gastrointestinal disorders are providing gastroprotection against many ulcerogens, and also accelerating ulcer healing. Generally, plants and fruits remarkably have many compounds that have antioxidant properties, such as carotenoids, ascorbic acid, and polyphenols (Shehata and Soltan 2013). Of these, avocado as an example of an important viable tropical fruit. It contains high levels of bioactive compounds such as ascorbic acid, carotenoids, vitamin E, and soluble phenolics (Lee et al., 2004). It is the fattiest plant fruit in the world (it contains monounsaturated fatty acids and lipids such as B-sitosterol, phytosterols, campesterol, and stigmasterol (Olagunju et al., 2017).

Kiwi fruits are highly nutritional fruits due to its high content of vitamin $\mathrm{C}$, in addition to its strong antioxidant also such as phenolics, carotenoids, lutein, flavonoids and chlorophyll (Cassano et al., 2006). Kiwi fruits are a rich source of fructose, galactose, vitamins $E$, and minerals. As well, they contain isoflavones and flavonoids (which consider important phytochemicals in kiwi extract and act as the major class of phytoestrogens) which play important roles as neuroprotective, anti-carcinogenic, and cardioprotective activity (Hunter et al., 2010).

With the remarkable characteristics of kiwi and avocado fruits, especially their high content of antioxidant compounds. Their fresh juices are widely consumed and may have a higher content of efficient anti-inflammatories and antioxidants than their extracts. Furthermore, there are no studies on using their fresh juices as anti-ulcer. The present study aimed to compare the effect of avocado and kiwi juices as anti-ulcer activities on Indo-induced gastric ulceration and to evaluate the histopathological effects of their fresh juices on stomach against Indo damage in rats.

\section{Materials and methods}

\section{Animals and Diet}

This study was conducted using thirty-six male albino rats "Sprague Dawley strain", with an initial weight of $185 \pm 10 \mathrm{~g}$. Rats were obtained from the Animal House Colony of the National Research Center, Dokki, Cairo, Egypt. They were kept in stainless steel cages at a well-ventilated animal house. 


\section{Egypt. J. of Nutrition and Health Vol. 14 No. 2 July (2019)}

\section{Plant Materials and Chemicals}

The fresh avocado and Hayward strain kiwifruit (the greatest common commercially available cultivar of kiwifruit in Egypt) were purchased from the local fruit and vegetable market in Kafr El-sheikh, Egypt. Indo was acquired from the NILE Company of Pharmaceuticals and Chemical IND (in Egypt). 1,1'-diphenyl-2-picrylhydrazyl (DPPH) and other chemical substances used for blood biochemical analysis were obtained from El-Gamhouria Company of Chemicals and Medical Appliances Trading, Cairo, Egypt.

\section{Preparation of juice}

The mature fresh fruits of kiwi and avocado were washed with tap water, peeled off and the flesh was homogenized using an electric blender to get the juices that were purified through a muslin fabric. The juices were prepared weekly and kept frozen in the form of small samples for daily use.

\section{Chemical analysis}

\section{Assessment of the total contents of phenolic and flavonoid}

Total phenolics in the fresh juices were measured based on the method adopted by Ben Nasr et al., (1996) and expressed as gallic acid equivalents (GAE). Also, the total content of flavonoid content in the juice samples was determined by the method of Ibrahim (2010). The flavonoid content was calculated and expressed as rutin equivalents. The determination of total contents of phenolic and flavonoid in the fresh juices were accomplished in triplicate and expressed as average.

\section{Antioxidant capacity measurement}

Antioxidant capacity was determined by the method of Thaipong et al., (2006). The antiradical action percentage toward the 2, 2-diphenyl-1 picrylhydrazyl (DPPH) was assessed by the difference in absorbance with or without the sample (i.e. control). The resulted values were expressed as the mean of triplicate analyses.

\section{Experimental Design}

Animals were acclimatized, for one week, to laboratory conditions before starting the experiment. During acclimatization and the whole period of the experiment, rats were fed on standard diet consisting of protein $21 \%$, fat $3.2 \%$ and fibers $3.44 \%$, according to the Nutrient Requirements of Laboratory Animals (1995). After the acclimation period, rats were randomly allocated into 6 groups, each group consists of 6 rats and treatments were as follows:

Group 1: Control group which received distilled water.(-ve Control)

Group 2: Indo (25 mg/kg/day) only (+ve Control)

Group 3: Kiwi juice (1.5 ml per day per rat) + Indo $(25 \mathrm{mg} / \mathrm{kg})$

Group 4: Kiwi juice ( $3 \mathrm{ml}$ per day per rat) + Indo $(25 \mathrm{mg} / \mathrm{kg})$

Group 5: Avocado juice (1.5 per day per rat) + Indo $(25 \mathrm{mg} / \mathrm{kg})$

Group 6: Avocado juice (3 per day per rat) + Indo $(25 \mathrm{mg} / \mathrm{kg})$

The fresh juice of fruits was given orally once daily for 21days. Indomethacin was dissolved in $5 \%$ sodium bicarbonate solution $\left(\mathrm{Na}_{2} \mathrm{HCO}_{3}\right)$ to create a clear solution. The dose of Indo was selected from published literature according to Ajeigbe et al., (2014). Indomethacin (Liometacen) is the most favored drug to generate an experimental ulcer model because its potential to make ulcer is higher than other NSAIDs. It causes damage to the gastric tissue by hindering the excretion of cytoprotective prostaglandin, mucus and bicarbonate, which increases the gastric acid secretion (Suleyman et al., 2010), and increased production of free radicals and reactive oxygen species (ROS) (Chattopadhyay et al., 2006). Administration of Indo induced gastric gross lesions, histological alteration and disruption 


\section{Amira L. Abd Allah}

in biochemical markers of oxidative markers with the reduction in antioxidant enzymes, and mucus in gastric tissue of rats (Albayrak et al., 2015).

\section{Biological evaluation}

During the 21 days period of the experiment, the quantities of diet consumed and/or wasted were recorded daily. Additionally, the rat's weight was noted weekly. Feed intake (FI), body weight gain $\%$ (BWG) and feed efficiency ratio (FER) were calculated at the end of the experiment according to the following equations as mentioned by Chapman et al., (1959) and Hosoya et al., (1980).

$\mathrm{FI}=$ Initial diet weight $(\mathrm{g})-$ left over diet weight $(\mathrm{g})$

$$
\begin{aligned}
\text { BWG }(\%) & =\frac{\text { Final weight }(\mathrm{g})-\text { initial weight }(\mathrm{g})}{\text { Initial weight }(\mathrm{g})} \times 100 \\
\mathrm{FER} & =\frac{\mathrm{BWG}(\mathrm{g}) / \text { day }}{\mathrm{FI}(\mathrm{g}) / \text { day }}
\end{aligned}
$$

\section{Assessment of gastric mucosal lesions}

At the end of the experiment, the rats were fasted all night before being sacrificed under anesthesia. The stomach of the sacrificed animals was removed and pinned flatly out flat on a cork surface, and the area of the ulcer on the stomach surface was calculated on the paper rulers scaled by $\mathrm{mm}^{2}$, as well, the ulcers on the stomach surface were macroscopically estimated. The gastric mucosal lesion is expressed regarding ulcer index (UI) accorded to Peskar et al. (2002) and Samyuktha et al. (2017) depending on the calculation of each lesion severity using a 0-3 score system defined based on the length of the lesions, where severity factor 0 means no lesions; severity factor 1 indicates lesions less than $1 \mathrm{~mm}$ length; severity factor 2 refers to lesions of 2-4 $\mathrm{mm}$ in length, while severity factor 3 indicates lesions larger than $4 \mathrm{~mm}$ in length. The lesions score was calculated for each rat as the number of the lesions in the rat $x$ their particular severity factor. The UI of each group was considered as the average lesion score of all group rats. The preventive index (PI) of the fresh juices of avocado and kiwi was calculated according to the Hano et al., (1976) equation as follow.

$$
\mathrm{PI}=[(\mathrm{UI} \text { of INDO group }- \text { UI of treated group }) \div \text { UI of INDO group }] \times 100
$$

Where

UI: Ulcer index

INDO: Indomethacin

\section{Determination of $\mathrm{pH}$ of gastric content}

One $\mathrm{ml}$ of the gastric juice was collected from each rat and the $\mathrm{pH}$ was directly measured by using digital $\mathrm{pH}$ meter ( $\mathrm{pH}-27 \mathrm{~B}, \mathrm{USA})$.

\section{Biochemical analysis}

The MDA levels in rat stomachs were determined by the method described in the study of (Ohkawa et al., 1979) and expressed as nmol/g wet tissue. Reduced glutathione (GSH) content was measured in the stomach homogenates as reported by Beutler et al. (1963) and expressed as $\mathrm{mg} / \mathrm{g}$ wet tissue. Stomach NO metabolites were determined based on the method adopted by Montgomery and Dymock (1961) and expressed as $\mu \mathrm{M} / \mathrm{g}$ wet tissue. In the acidic medium and the presence of nitrite, the formed nitrous acid diazotize sulfanilamide and the product is combined with N-(1-naphthyl) ethylenediamine. The developing azo dye with a bright reddish-purple color can be measured at 540 $\mathrm{nm}$ wavelength. 
Egypt. J. of Nutrition and Health Vol. 14 No. 2 July (2019)

\section{Histopathology Examinations}

For histology examination, the stomach of all animal groups was collected immediately after scarifying and fixed in formalin (10\%) for at least $24 \mathrm{~h}$ and then dehydrated by washing in ascending levels of ethanol before clearing with xylene and embedding in paraffin wax. The microtome (Spinco, India) was used to section the samples that stained with hematoxylin and eosin (HE) for investigation under a light microscope to examine the histopathological changes. Photomicrographs of chosen lesions were taken in each tissue at different magnifications using a digital camera fitted to a light microscope as reported by Taiwo and Anosa (2000).

\section{Statistical analysis}

Statistical analysis was performed using the program of Statistical Package for the Social Sciences software (SPSS) version 18. The results were expressed as mean \pm Standard deviation (mean \pm S.D.). Data were analyzed using one-way ANOVA (Snedecor and Cochran, 1979).

\section{Results}

Total phenolic, total flavonoid contents and total antioxidant activity in kiwi and avocado juice

Table (1): Shows that the total phenolic, total flavonoid and total antioxidant contents in kiwi juice recorded the highest concentration than avocado juice. Also, total antioxidant activity was higher in kiwi juice than avocado juice.

Table (1)

Total phenolic, total flavonoid contents and total antioxidant activity in kiwi and avocado juice

\begin{tabular}{c|c|c|c}
\hline Fruits & $\begin{array}{c}\text { Total phenolic } \\
(\mathrm{GAE} \mathrm{mg} / \mathrm{g} \mathrm{FW})\end{array}$ & $\begin{array}{c}\text { Total flavonoid } \\
(\mathrm{RE} \mathrm{mg} / \mathrm{g} \mathrm{FW})\end{array}$ & $\begin{array}{c}\text { Total antioxidant activity by } \\
\text { DPPH\% }\end{array}$ \\
\hline Kiwi juice & $11.65 \pm 1.20$ & $5.84 \pm 0.69$ & $74.13 \pm 0.97$ \\
\hline Avocado juice & $6.57 \pm 0.89$ & $4.57 \pm 0.34$ & $63.54 \pm 1.09$ \\
\hline
\end{tabular}

FW: Fresh weight; GAE: Gallic acid equivalent; RE: Rutin equivalents.

Values are expressed as mean $\pm S D(n=3)$.

\section{Effect of juices of kiwi and avocado on FI, BWG \% and FER}

From data in Table (2) it could be observed that the mean value of $\mathrm{FI}, \mathrm{BWG} \%$ and $\mathrm{FER}$ of $(+\mathrm{ve})$ control group (Indo treated group only) were lower than (-vec) normal group, but oral administrations of juices (kiwi juice or avocado juice) showed a significant increase $(P<0.05)$ in $\mathrm{Fl}$, BWG. On the other hand, insignificant differences were noticed between groups treated with fruit juices for increasing FER as compared to Indo treated group only. 
Amira L. Abd Allah

Table (2)

Effect of kiwi juice and avocado juice on FI, BWG \% and FER Indo-induced ulcer model

(Mean \pm SD)

\begin{tabular}{|c|c|c|c|}
\hline Groups & $\mathrm{Fl} /$ day & BWG\% & FER \\
\hline Normal group (-ve c) & $25.55^{\mathrm{a}} \pm 2.102$ & $17.78^{\mathrm{a}} \pm 1.890$ & $0.062^{a} \pm 0.006$ \\
\hline Indo $(25 \mathrm{mg} / \mathrm{kg})(+\mathrm{ve} \mathrm{c})$ & $7.33^{C} \pm 0.575$ & $4.39^{d} \pm 0.282$ & $0.051^{b} \pm 0.004$ \\
\hline Kiwi juice $(1.5 \mathrm{ml})$ & $9.19^{C} \pm 1.259$ & $10.81^{b} \pm 1.090$ & $0.055^{b} \pm 0.003$ \\
\hline Kiwi juice (3 ml) & $17.03^{b} \pm 0.991$ & $10.54^{b} \pm 1.314$ & $0.052^{b} \pm 0.006$ \\
\hline Avocado juice (1.5 ml) & $15.42^{b} \pm 1.900$ & $8.06^{C} \pm 0.670$ & $0.049^{b} \pm 0.012$ \\
\hline Avocado juice (3 ml) & $17.25^{\mathrm{b}} \pm 2.250$ & $7.34^{c} \pm 0.429$ & $0.035^{c} \pm 0.008$ \\
\hline
\end{tabular}

highly significant.

Effect of avocado juice and kiwi juice on the development of gastric Lesions:

Indomethacin caused severe damage to stomach of the rats and reduction in the $\mathrm{pH}$ value of gastric juice with increase in ulcer index (UI) of $(10.13 \pm 1.15)$, while the treatment with fruit juices (kiwi and avocado) significantly reduced the UI when compared to untreated Indo administration control group and increases the $\mathrm{pH}$ acidity significantly compared with normal group. Also, treatment with a high dose of kiwi juice and avocado juice at dose 1.5 and $3 \mathrm{ml} /$ day prevented the formation of ulcers by $57.26,70.38$ and $73.54 \%$ respectively (Table 3 ).

Table (3)

Effect of kiwi juice and avocado juice on $\mathrm{pH}$, ulcer index (UI) and preventive index (PI \%) in indomethacin-induced ulcer model (Mean \pm SD)

\begin{tabular}{l|c|c|c}
\hline Groups & $\mathrm{pH}$ & $\mathrm{Ul}$ & $\mathrm{Pl} \%$ \\
\hline Normal group(-vec) & $5.08^{\mathrm{a}} \pm 0.096$ & $0.00 \pm 0.00$ & -- \\
\hline Indo $(25 \mathrm{mg} / \mathrm{kg})(+\mathrm{vec})$ & $2.68^{\mathrm{e}} \pm 0.187$ & $10.13^{\mathrm{a}} \pm 1.15$ & 00 \\
\hline Kiwi juice $(1.5 \mathrm{ml})$ & $3.07^{\mathrm{d}} \pm .0228$ & $8.43^{\mathrm{a}} \pm 1.07$ & 16.78 \\
\hline Kiwi juice $(3 \mathrm{ml})$ & $3.59^{\mathrm{c}} \pm 0.179$ & $3.00^{\mathrm{b}} \pm 1.00$ & 70.38 \\
\hline Avocado juice $(1.5 \mathrm{ml})$ & $3.62^{\mathrm{c}} \pm 0.232$ & $4.33^{\mathrm{b}} \pm 1.53$ & 57.26 \\
\hline Avocado juice $(3 \mathrm{ml})$ & $4.12^{\mathrm{b}} \pm 0.052$ & $2.68^{\mathrm{b}} \pm 0.58$ & 73.54 \\
\hline
\end{tabular}

Means with the same letter are not significantly different, $(P<0.05)$ is significant and $(P<0.01)$ is highly significant.

\section{Biochemical findings}

Oral administrations of kiwi juice and avocado juice at dose 1.5 and $3 \mathrm{~mL} /$ day showed a significant decrease in MDA concentration induced by Indo. As well, there was a significant increase in the levels of NO and GSH in stomach tissue when compared with Indo treated group only. A high dose of avocado juice ( $3 \mathrm{ml}$ per day) was the best result, where it recorded values close to the normal control group (Table 4). 
Table (4)

Effect of kiwi juice and avocado juice on Malondialdeehyde (MDA), Nitric oxide (NO) and reduced glutathione (GSH) in indomethacin-induced ulcer model in rat gastric tissue

(Mean \pm SD)

\begin{tabular}{l|c|c|c}
\hline Groups & MDA nmol/g. tissue & NO $\mu \mathrm{mol} / \mathrm{g}$ & GSH mmol/g. tissue \\
\hline Normal group & $2.11^{\mathrm{e}} \pm 0.161$ & $4.06^{\mathrm{a}} \pm 0.282$ & $1.89^{\mathrm{a}} \pm 0.156$ \\
\hline Indo $(25 \mathrm{mg} / \mathrm{kg})$ & $5.84^{\mathrm{a}} \pm 0.290$ & $0.84^{\mathrm{e}} \pm 0.066$ & $0.96^{\mathrm{e}} \pm 0.070$ \\
\hline Kiwi juice $(1.5 \mathrm{ml})$ & $4.85^{\mathrm{b}} \pm 0.195$ & $1.62^{\mathrm{d}} \pm 0.109$ & $1.14^{\mathrm{d}} \pm 0.095$ \\
\hline Kiwi juice $(3 \mathrm{ml})$ & $4.12^{\mathrm{c}} \pm 0.193$ & $2.33^{\mathrm{bc}} \pm 0.223$ & $1.36^{\mathrm{c}} \pm 0.056$ \\
\hline Avocado juice $(1.5 \mathrm{ml})$ & $4.37^{\mathrm{c}} \pm 0.087$ & $2.00^{\mathrm{cd}} \pm 0.174$ & $1.19^{\mathrm{d}} \pm 0.070$ \\
\hline Avocado juice $(3 \mathrm{ml})$ & $3.68^{\mathrm{d}} \pm 0.140$ & $2.69^{\mathrm{b}} \pm 0.526$ & $1.52^{\mathrm{b}} \pm 0.045$ \\
\hline
\end{tabular}

MDA: Malondialdeehyde; NO: Nitric oxide; GSH: Glutathione

Data are represented as mean $\pm S$.E. Means with same letter are not significantly different

\section{Microscopic examination of gastric sections}

Microscopic examination of gastric sections showed normal histological pictures in the control group, vascular congestion, gastric erosion/ulceration and glandular necrosis in the group received Indo (Figures 1a-f) and (Figures 2a-f). Histopathological lesions were observed in other experimental animals but they varied in severity among the treated groups (Table 5).

Table (5)

Scoring of stomach histological lesions in the experimental groups

\begin{tabular}{c|c|c|c|c|c|c}
\hline Groups & Normal & Indo & $\begin{array}{c}\text { Kiwi juice } \\
(1.5 \mathrm{ml})\end{array}$ & $\begin{array}{c}\text { Kiwi juice } \\
(3 \mathrm{ml})\end{array}$ & $\begin{array}{c}\text { Avocado } \\
\text { juice }(1.5\end{array}$ & $\begin{array}{c}\text { Avocado } \\
\text { juice }(3 \mathrm{ml})\end{array}$ \\
\hline $\begin{array}{c}\text { Submucosal } \\
\text { Congestion/edema }\end{array}$ & - & +++ & ++ & + & + & - \\
\hline $\begin{array}{c}\text { Submucosal } \\
\text { inflammation }\end{array}$ & & & ++ & + & + & - \\
\hline Glandular necrosis & - & +++ & - & - & - & - \\
\hline Erosions/ulcers & - & ++ & - & - & - & - \\
\hline
\end{tabular}

(-) no lesions observed; ( \pm ) mild, focal lesions; (+) moderate, multifocal lesions; (++) moderately severe, diffuse lesions; (+++) very severe, diffuse lesions 


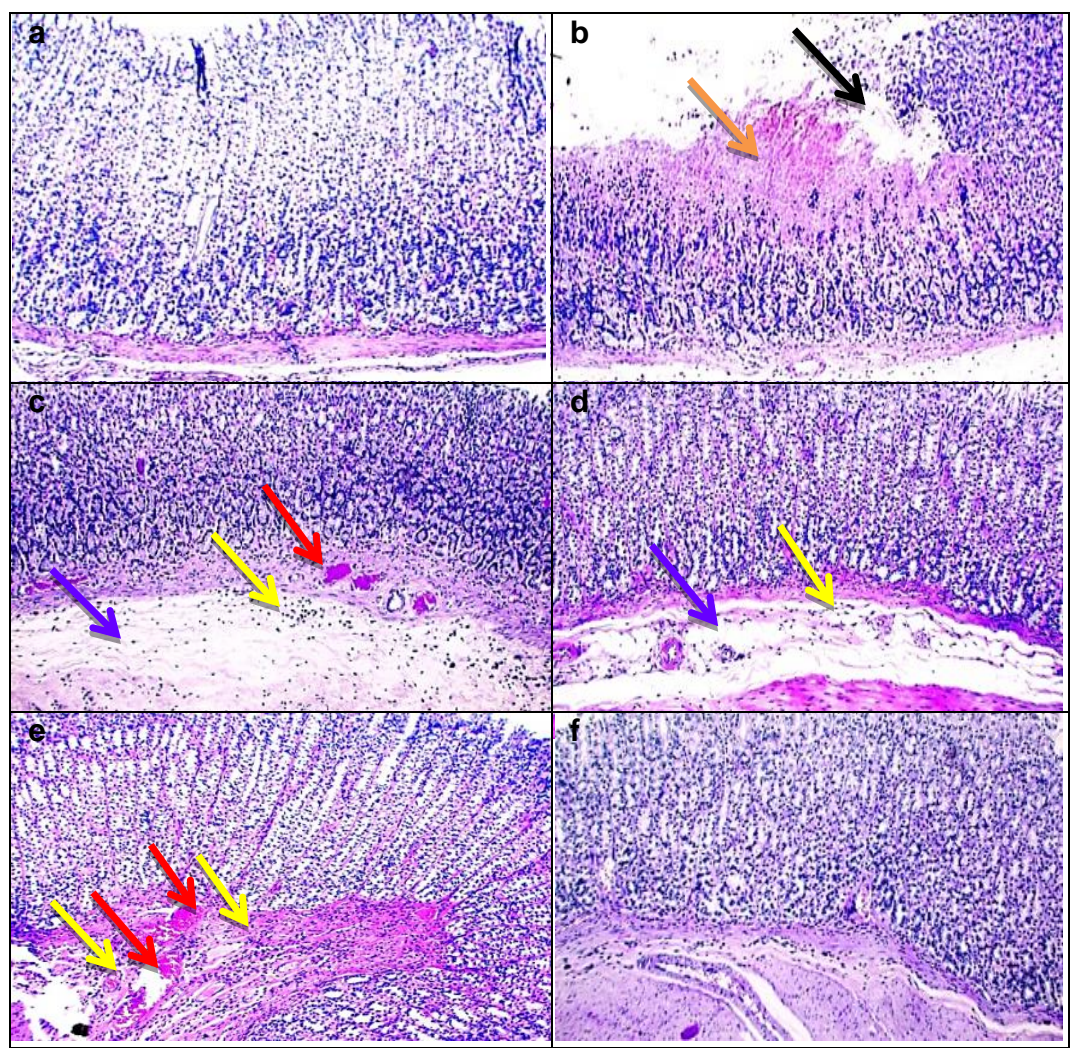

Fig. (1): Histological evaluation of rats' gastric tissues treated with Indo and fresh juices of kiwi and avocado (H\&E, X100): (a) Normal group. (b) Indo group (25 $\mathrm{mg} \mathrm{kg}^{-1}$ ). (c) Kiwi juice (1.5 ml once daily). (d) Kiwi juice (3 $\mathrm{ml}$ once daily). (e) Avocado juice (1.5 $\mathrm{ml}$ once daily). (f) Avocado juice (3 $\mathrm{ml}$ once daily).

The orange arrow (necrosis), the black arrow (ulceration), a blue arrow (submucosal edema), the yellow arrow (inflammation) and red arrow (congestion). 
Egypt. J. of Nutrition and Health Vol. 14 No. 2 July (2019)

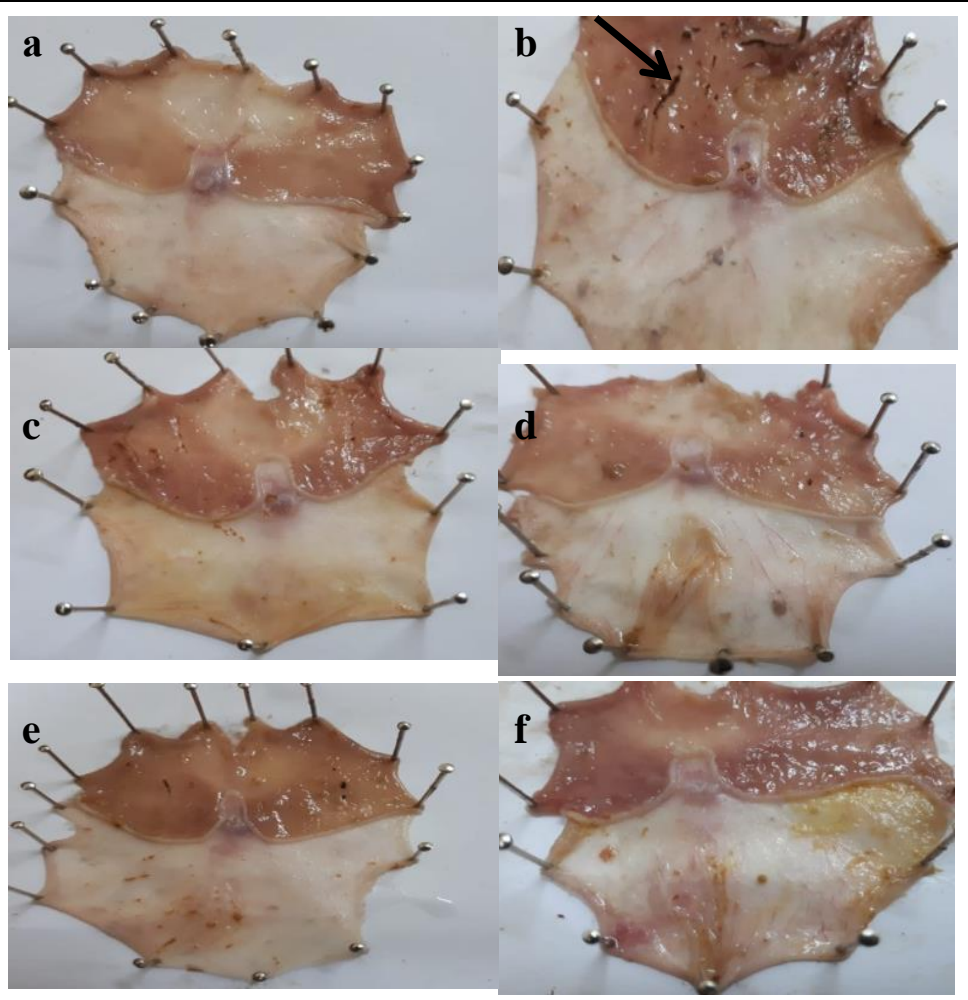

Fig. (2): (a) Gastric mucosa of normal rats showing the absence of ulcers. (b) Gastric mucosa of untreated rats showing severe ulceration. (c) Gastric mucosa of kiwi juice group (1.5 ml) showing less intense ulceration. (d) Gastric mucosa of kiwi juice group (3 ml) showing mild ulceration. (e) Gastric mucosa avocado juice group (1.5 ml) mild ulceration. (f) Gastric mucosa avocado juice group (3 ml) showing the absence of ulcers.

\section{Discussion}

The presence of phenolic and flavonoids compounds especially at a high concentration correlates with the increase in antioxidant activity of fruits (Patel et al., 2015). It can be concluded from the study that kiwi juice and avocado juice have a higher content of phenolics and flavonoids which has increased their antioxidant capacity that is observed in DPPH assays. These results agreed with previous findings of Gorinstein et al., (2011) who found higher phenolic compounds of kiwi fruit extract. Additionally, Patel et al., (2015) concluded that the kiwi fruit had the highest content of flavonoids which contributes to its antioxidant activity. Also, Venter (2013) and Alghamdi and Yousef (2017) indicated that avocado has the main source of several types of natural antioxidants such as vitamins $C, E$, and $\beta$-carotene which protect lipid peroxidation in the body.

The reduction in FI BWG, and FER for the Indo group $(\mathrm{C}+)$ was attributed to peptic ulcer in this group; where gastric ulcer may be led to malnutrition due to poor dietary intake, maldigestion, malabsorption, and abnormalities in the metabolism. This is in line with previous findings by Tahoon and EI Sheikh (2016) who reported that FI, BWG, and FER were decreased in ulcer peptic group than normal control.

In the present study, the administration of fruit juices caused an increase in FI and BWG compared with the Indo group. Meanwhile, there is no significant difference observed in the FER of 


\section{Amira L. Abd Allah}

groups treated with juices compared with ulcer group. The reduction in BWG of avocado juices may be due to high phenolic content in addition to its content of polyunsaturated fatty acids, which was reported to be present in avocado. These results agreed also with the recorded data of Naveh et al., (2013) who found that that avocado consumption is associated with improved FI and lower BWG. Also, Alghamdi and Yousef (2017) concluded that the avocado at 15\% and 25\% has protective effect against overweight.

In this study, the effect of indomethacin on the gastric lesions of rats matches with the finding of Hamad (2015) who found that gastric tissues in animals treated with Indo showed prominent areas of ulceration and erosion in mucosa with dilated congested blood vessels and edema in sub-mucosal layers. The observed gross lesions and histological alteration in gastric tissues of the experimental animals could be attributed to the activation of inflammatory cells infiltration (Abdel-Raheem, 2010) or inhibition of prostaglandins production and their therapeutic actions through inhibition of cyclooxygenase (COX) enzyme (Chatterjee et al., 2013). Suppression of prostaglandin synthesis is associated with a reduction of gastric mucosal blood flow, disturbance of microcirculation, decrease in mucus secretion, enhancement of lipid peroxidation and neutrophil activation, which are involved in the pathogenesis of gastrointestinal mucosal disorders (Wallace, 2008). Also, the present results showed that treatment with kiwi juice or avocado juice resulted in the improvement of gastric lesions induced by Indo as revealed by histological examination. This amelioration was evident by normal appearance of gastric tissue and marked decline in ulcer index and increase in $\mathrm{pH}$ value, preventive index (PI), and was evident histologically by reappearance of normal mucosa layer (no lesion) in the group treated with the high dose of avocado juice compared to Indo group: Low dose $(1.5 \mathrm{ml})$ of fruit juice was less effective than $3 \mathrm{ml}$ per day in improving gastric lesions, and $3 \mathrm{ml} / \mathrm{day}$ of avocado juice was more effective than $3 \mathrm{ml} /$ day of kiwi juice. These results are consistent with Hamad (2015) who revealed that treatment with kiwi fruit extract (KFE) resulted in improvements of gastric gross lesions induced by Indo in a dose-dependent manner as revealed by gross and histological examination in her study.

This finding is supported by previous studies which assumed that avocado was recognized to overpower the inflammatory response through declining the inflammatory genes expression. As well, it could preserve the integrity of cellular membranes. Where, avocado fruit is characterized by having high levels of lipid than in other fruits. Most lipids found in avocados are polar lipids (glycolipids and phospholipids), which play a vital role in various cellular processes (Wang et al., 2015). Previous studies ascribed the antioxidant and the anti-inflammatory effects of avocado to its oil, which reduces the pro-inflammatory cytokines activity and the ROS generation through damaging mitochondria (Duarte et al., 2016). Similarly, Dreher and Adrienne (2013) found that the avocado contains $71 \%$ of monounsaturated fatty acids (MFA) $13 \%$ of polyunsaturated fatty acids (PUFA), and $16 \%$ of saturated fatty acids (SFA), that help to promote healthy blood lipid profile and enhance the bioavailability of fatsoluble vitamins and phytochemicals consumed with avocado. Arumugasamy et al., (2015) showed that PUFA has a significant anti-ulcer and cytoprotective effect on various experimentally induced gastric lesions. This could effectively help resolve the inflammation and promote a transition from the inflammatory to the proliferative and remodeling phases of wound healing. The anti-inflammatory property of kiwi fruit is attributed to inhibition of inducible nitric oxide synthase, expressions of cyclooxygenase 2 enzyme ( Ren et al., 2007), and increasing the mucosal prostaglandin content through their flavonoid content (Borrelli and Izzo, 2000). Prostaglandins have cytoprotective effects on gastric mucosa (Brandt, 1991). Micronutrients such as vitamins $C$ and $E$, as well as carotenoids and phenolic compounds of kiwifruit, are able to scavenge free radicals and also can delay or inhibit the oxidation of both lipids and other molecules by suppressing the initiation/ propagation steps of oxidative chain reactions (Al Naimy et al., 2012). 


\section{Egypt. J. of Nutrition and Health Vol. 14 No. 2 July (2019)}

Oxidant and antioxidant parameters are used to evaluate the biochemical effect of Indo on the stomach (Allam and El-Gohary 2017). As can be conducted from present results, oxidant parameter levels such as MDA in the Indo group with larger UI showed a significant increase compared to the healthy, or for groups treated with fruit juices highly significant decrease of NO and GSH in gastric tissues. It is reported by Albayrak et al. (2015) that the antioxidant parameters decrease in the experimental damaged stomach tissue and oxidized parameters increases because administration of Indo decreased the antioxidants enzymes (i.e. GSH, GPX, CAT, and SOD) associated with an increase in MDA concentration in stomach tissue of rats. Also, Gomaa et al., (2018) reported that the MDA level increases in the damaged stomach tissue due to Indo treatment. As well, Suleyman et al., (2018) stated that Indo changed the oxidant-antioxidant balance in stomach tissue in favor of oxidants. This literature information demonstrates the importance of maintaining oxidant-antioxidant balance with the superiority of antioxidants. It also reveals that the relationship between antioxidant activity and the anti-ulcer effect is important. The reduction in NO by Indo, in the current study could be attributed to the reduction of endothelial nitric oxide synthase (eNOS) activity and overexpression of inducible nitric oxide synthase (iNOS) (Souza et al., 2008). In the digestive system, nitric oxide produced by eNOS is cytoprotective and that produced by iNOS is cytotoxic (Motawi et al., 2007). Similarly, Ma and Wallace (2000) found that eNOS plays a considerable role in gastric ulcer healing while its inducible isoform does not. The observed reduction in antioxidant enzymes by Indo administration could be attributed to the pro-oxidant activity of Indo, which initiates the generation of free radicals/reactive oxygen species (ROS), thus interferes with the endogenous antioxidant systems (La Framboise et al., 2006). Current study reveals that all fruit juice treatments (i.e. 1.5 and $3 \mathrm{ml} /$ day) increased the $\mathrm{NO}$ and GSH content significantly and reduced the MDA level. This affected positively the antioxidant defense system and reduced gastric damage. As the oxidant-antioxidant balance in stomach tissues of kiwi and avocado juice groups resulted in the superiority of antioxidants. For juice doses of the highest anti-ulcer activity (i.e. $3 \mathrm{ml} /$ day), the gastric GSH level is higher than those for doses with lower activity (i.e. 1.5 $\mathrm{ml} /$ day) and $3 \mathrm{ml} /$ day of avocado juice was more effective than $3 \mathrm{ml} /$ day of kiwi juice. GSH protects gastrointestinal tissue lipids from oxidative damage. As demonstrated by Bilici et al. (2009) in gastric tissue damaged by Indo, the GSH level is lowered.

These findings are in agreement with Emam and Hegazy (2015) who revealed that avocado improves the enzymatic and non-enzymatic antioxidant defense status as increased catalase activity, vitamin $\mathrm{C}, \mathrm{A}$ and $\mathrm{E}$. It could also attenuate the lipid peroxide products as MDA due to its free radical scavenging action. Moreover, Hamad (2015) revealed that treatment with KFE markedly reduced the level of lipid MDA and increased levels of NO and GSH which disrupted by Indo treatment. Sadek et al., (2012) reported that consumption of kiwi fruit ameliorated histological changes of colon cancer induced chemically, attenuates the severity of oxidative colonic damage and lipids profile and also elevated antioxidant enzymes levels together with reducing MDA in plasma and colon in rats. The observed beneficial effects of kiwi fruit extract (KFE) against toxicity of Indo could be attributed to its antioxidant, anti-inflammatory properties (Ciacci et al., 2014). Kiwi fruit is a highly nutritional fruit and has stronger anti-oxidative effects than other fruits (Kang et al., 2012). It contains strong antioxidants as high levels of phenolics, vitamins (C, A, B2, and E), many minerals, carotenoids, flavonoids, chlorophyll, terpenoids and fiber (Collins, 2013). Its isoflavones and flavonoids have important functions as anti-carcinogenic, neuro-protective and cardio-protective activity (Dehghani et al., 2006). The potential antioxidant property of kiwi fruit is most often attributed to its rich source of potentially antioxidant polyphenols and flavonoids (Lim, 2012). 


\section{Conclusion and recommendation}

Indo caused severe damage to the gastric tissue of rats as proved by biochemical and histological results. It could be concluded that using high doses of avocado and kiwi juices were effective in preventing or relieving peptic ulcers induced by Indo and its other side effects. This effect may be due to high content of phenolics and flavonoids compounds in these juices. According to these results, tested juices could be used for protection from peptic ulcer caused by Indo.

\section{References}

Abdel-Raheem, I. T. (2010):

Gastroprotective effect of rutin against indomethacin-induced ulcers in rats. Basic \& Clinical Pharmacology \& Toxicology, 107: 742-750.

Ajeigbe, K.O.; Onifade, A. A.; Omotoso, D.R.; Enitan, S.S.,and Olaleye, S.B. (2014):

Anti-ulcerogenic activity of aspilia africana leaf extract: Roles of gastric acid, oxidative stress and neutrophil infiltration. Afr. J.Biomed. Res., 1(7):193-201.

Al Naimy, E. H.; Al-Lihaibi, R. K.; Majeed, S. M. and Al-Ani, R. S. (2012):

Antibacterial and cytotoxic effects of the kiwi fruit and pomegranate active compounds on tumor cell line (I20b, rd). The Iraqi Journal of Agricultural Sciences, 43 (1): 157-167.

Albayrak, A.; Hamit H. Alp, H. H. and Suleyman, H. (2015):

Investigation of antiulcer and antioxidant activity of moclobemide in rats. Eurasian J. Med., 47: $32-40$.

Alghamdi, E. S., and Yousef, F. M. A. (2017):

Effect of Avocado on Serum Lipids of Hyperlipidemic Rats. Curr. Sci. Int., 6(1): 199-207.

Allam, M.M., and El-Gohary, O.A. (2017):

Gastroprotective effect of ghrelin against indomethacin-induced gastric injury in rats: Possible role of hemeoxygenase-1 pathway. Gen. Physiol. Biophys., 36:321-330.

Arumugasamy, K.; Kannan, S.; Vor, P.A. and Tyag, M. G. (2015):

Anti-ulcer activity of arachidonic acid (PUFA) oils in different induced ulcer animal models. Int. J. Res. Med. Sci., 3(5):1142-1148.

Ben Nasr, C.; Ayed, N. and Metche M. (1996):

Quantitative determination of the polyphenolic content of pomegranate peel. Z Lebensm Unters Forsch; 203:374-378.

Beutler, E.; Duron, O. and Kelly M.B. (1963):

Improved method for the determination of blood glutathione. J. Lab. Clin. Med., 61; 882.

Bilici, M.; Ozturk, C; Dursun, H. et al. (2009):

Protective effect of mirtazapine on indomethacin-induced ulcer in rats and its relationship with oxidant and antioxidant parameters. Dig. Dis. Sci., 54:1868-75. 
Egypt. J. of Nutrition and Health Vol. 14 No. 2 July (2019)

Borrelli, F. and Izzo, A. A. (2000):

The plant kingdom as source of antiulcer remedies. Phytother. Res., 14(8): 581-591.

Brandt, K. D. (1991):

The mechanism of action of NSAIDs. J. Rheumatol., 18: 120-121.

Cassano, A.; Figoli, A. A.; Tagarelli, Sindono G. and Drioli, E. (2006):

Integrated membrane process for the production of highly nutritional kiwi fruit juice. Desalination, 189: 21-30.

Chan, F. K. (2006):

Primer: Managing NSAID-induced ulcer complications-balancing gastrointestinal and cardiovascular risks. Nat. Clin. Pract. Gastroenterol. Hepatol., 3: 563-573.

Chapman, D.G.; Castilla, R. and Cambell, A.J. (1959):

Evaluation of protein in food. In: Method for the Documentation of protein Efficiency Ratio. Can. J. Biochem. Physiol., 37; 679-686.

Chatterjee, A.; Khatua, S.; Chatterjee, S.; Mukherjee, S.; Mukherjee, A.; Paloi, S.; Acharya, K. and Bandyopadhyay, S. K. (2013):

Polysaccharide-rich fraction of Termitomyces eurhizus accelerate healing of indomethacin induced gastric ulcer in mice. Glycoconj J., 30(8): 759-768.

Chattopadhyay, I.; Bandyopadhyay, U.; Biswas, K.; Maity, P. and Banerjee, R. K. (2006):

Indomethacin inactivates gastric peroxidase to induce reactive oxygen- mediated gastric mucosal injuty and curcumin protects it by preventing peroxidase inactivation and scavenging reactive oxygen. Free Radic. Biol. Med., 40(8): 1397-1408.

Ciacci, C.; Russo, I.; Bucci, C.; lovino, P.; Pellegrini, L.; Giangrieco, I.; Tamburrini , M. and Ciardiello, A. (2014):

The kiwi fruit peptide kissper displays anti-inflammatory and anti-oxidant effects in in-vitro and ex-vivo human intestinal models. Clin. Exp. Immunol., 175(3): 476-84.

Collins, A. R. (2013):

Kiwifruit as a modulator of DNA damage and DNA repair. Adv. Food Nutr. Res., 68: 283-299.

Darbar, S. (2010):

Antiulcer effect of livina, a herbal formulation against ethanol induced acute gastric ulcer in mice. International journal of pharma. research \& development-online (ijprd): 9974 -9446.

Dehghani, F.; Talaei-Khozani, T.; Panjehshahin, M. R. and Panahi, Z. (2006):

Toxic effects of hydroalcoholic extract of kiwi (Actinidia chinensis) on histological structure of the male sprague-dawley rat reproductive tissues. Iranian Journal of Science \& Technology, Transaction A, 30(1): 19-25.

Dreher, M. and Adrienne, J. (2013):

Hass Avocado Composition and Potential Health Effects. Critical Reviews in Food Science and Nutrition, 53:738-750. 
Duarte, P.F.; Chaves, M.A.; Borges, C.D., and Mendonca, C.R.B. (2016):

Avocado: Characteristics, health benefits and uses. Ciencia Rural, 46(4):747-754.

Emam, M.A., and Hegazy, M.G.A. (2015):

Cardioprotective effect of Persea americana mill fruit extract in experimental myocardial infarction. World Journal of Pharmaceutical Research, 4 (10): 2552-2567.

Garlord, S. and Crotty, N. (2002):

Enhancing function with complementary therapies geriatric rehabilitation. Top Geriatr. Rehabil, 18:63-80.

Gomaa, A.M.; El-Mottaleb, N.A.A., and Aamer, H.A.(2018):

Antioxidant and anti-inflammatory activities of alpha lipoic acid protect against indomethacininduced gastric ulcer in rats. Biomed Pharmacother., 101:188-94.

Gorinstein, S.; Sumitra, P.; Hanna, L.; Maria, L.; Jacek, N.; Suchada, V.; Ratiporn, H.; Pramoj, R.; Elena, K. and Zer, T. ( 2011):

Antioxidant properties and bioactive constituents of some rare exotic Thai fruits and comparison with conventional fruits in vitro and in vivo studies. Food Research International, 44: 2222-2232.

Hamad, S. R. (2015):

Protective Role of Kiwifruit on Gastro-Hepatotoxicity of Indomethacin. M. SC. Thesis, Faculty of Science, Cairo University.

Hano, J.; Bugajski, J. and Danek, L. (1976):

Effect of adrenergic blockade on gastric secretion altered by catecholamines in rats. Arch. Immunol. Ther. Exp. (Warsz), 24:507-524.

Hosoya, N., Inami, S., and Goto, S. (1980):

Determination of feed efficiency ratio. Nutrition Experiments Using Small Animals. Daiichi Shuppan, Tokyo, Japanese, pp:71.

Hunter, D.C.; Skinner, M.A.; Ferguson, A.R. and Stevenson, L.M. (2010):

Kiwi Fruit and Health. The New Zealand Institute for Plant and Food Research Itd. Auckland, New Zealand, 2 Edition, 565 -580.

Ibrahim, M.I. (2010):

Efficiency of pomegranate peel extract as antimicrobial, antioxidant and protective agents. World J Agric. Sci.; 6:338-344.

Kang, W.; Yang, H.; Hong, H. J.; Han, C. H., and Lee, Y. J. (2012):

Anti-oxidant activities of kiwi fruit extract on carbon tetrachloride-induced liver injury in mice. Korean J. Vet. Res., 52(4): 270-280. 
Egypt. J. of Nutrition and Health Vol. 14 No. 2 July (2019)

Kuna, L.; Jakab, J.; Smolic, R.; Raguz-Lucic, N.; Vcev, A. and Smolic, M. (2019):

Peptic ulcer disease: a brief review of conventional therapy and herbal treatment options. J. Clin. Med., 8: 1-19.

La Framboise, W. A.; Bombach, K. L.; Pogozelski, A. R.; Cullen, R. F.; Muha, N.; LyonsWeiler, J.; Spear, S. J.; Dhir, R.

J.; Guthrie, R. D. and Magovern, J. A. (2006):

Hepatic gene expression response to acute indomethacin exposure. Molecular Diagnosis and Therapy,10: 187-196.

Lanas, A. and Chan, F.K.L. (2017):

Peptic ulcer disease. Lancet, 390, 613-624.

Lanas, Á.; Carrera-Lasfuentes, P.; Arguedas, Y.; Garcĺa, S.; Bujanda, L.; Calvet, X.; Ponce, J.; Perez-Aísa, Á.; Castro,

M.; Muñoz, M. et al., (2015):

Risk of upper and lower gastrointestinal bleeding in patients taking nonsteroidal antiinflammatory drugs, antiplatelet agents, or anticoagulants. Clin. Gastroenterol. Hepatol., 13:906-912.

Lee, J.; Koo, N. and Minm, D. (2004):

Reactive oxygen species, aging, and antioxidative nutraceuticals. Comprehensive Review in Food Science and Food Safety, 3: 21- 33.

Lim, T. K. (2012):

Edible Medicinal and Non-Medicinal Plants (Fruit). 1st Edition. New York., 20-29.

Ma, L. and Wallace, J. L. (2000):

Endothelial nitric oxide synthase modulates gastric ulcer healing in rats. Am. J. Physiol. Gastrointest. Liver Physiol., 279:G341-G346.

Montgomery, H. A.C., and Dymock, J. F. (1961):

Colorimetric determination of nitrite. Analyst, 86: 414.

Motawi, T. K.; Abd Elgawad, H. M. and Shahin, N. N. (2007):

Modulation of indomethacin-induced gastric injury by spermine and taurine in rats. J. Biochem. Mol. Toxicol., 21:280-288.

Nalamachu, S. and Wortmann, R. (2014):

Role of indomethacin in acute pain and inflammation management: A review of the literature. Postgrad Med., 126(4): 92-97.

Narayanan, M.; Reddy, K.M.; Marsicano, E. (2018):

Peptic ulcer disease and Helicobacter pylori infection. Mo. Med.,115: 219-224.

Naveh, E.; Werman, M.; Sabo E. and Neeman, I. (2013):

Defatted Avocado Pulp Reduces Body Weight and Total Hepatic Fat But Increases Plasma Cholesterol in Male Rats Fed Diets with Cholesterol. J. nutrition. org. 2015- 2018. 
Ohkawa, H.; Ohishi, W. and Yagi, K. (1979):

Assay for lipid peroxides in animal tissues by thiobarbituric acid reaction. Anal. Biochem., 95: 351-358.

Olagunju, H.T.; Oruambo, I. F.; Oyelowo, H.O., and Obediah, G.A. (2017):

Effects of some selected solvent extracts of avocado pear (persea americana) on cholesterol/hdl ratio in albino rats. Biochem. Anal. Biochem., 6(4): 342.

Patel, I.; Padse, O. and Ingole, Y.(2015):

Comparative analysis of antioxidant and antidiabetic activity for apple (Malus domestica), banana (Musa paradisiaca) \& kiwi (Actinidia deliciosa). International Journal of Research in Advent Technology (E-ISSN: 2321-9637) Special Issue National Conference "ACGT 2015", 13-14.

Peskar, B.M.; Ehrlich, K. and Peskar, B.A. (2002):

Role of ATP-sensitive potassium channels in prostaglandin-mediated gastroprotection in the rat. J. Pharmacol. Exp. Ther., 301:969-974.

Ren, J.; Han, E. and Chung, S. (2007):

In vivo and in vitro anti-inflammatory activities of alpha-linolenic acid isolated from Actinidia polygama fruits. Arch. Pharm. Res., 30: 708-714.

Rivera, J. O.; Loya, A. M. and Ceballos, R. (2013):

Alternative and integrative medicine use of herbal medicines and implications for conventional drug therapy medical sciences. Altern. Integ. Med., 2(6): 1 -6.

Robinson, M. M., and Zhang, X. (2011):

Traditional medicines: Global situation, issues and challenges. The world medicines situation (3rdedn) WHO Geneva, 1-14.

Ryan, S.W. (2005):

Management of dyspepsia and peptic ulcer disease. Alternative Therapies in Health and Medicine, 11(5): 26-29.

Sadek, M. A.; Aref, M. I.; Khalil, F. A.; Barakat, L. A. A.; Ali, N. H. and Soliman, B. S. M. (2012): Impact of Actinidia deliciosa (Kiwi fruit) consumption on oxidative stress status in carcinogenesis. African J. Biol. Sci., 8(1): 117-127.

Samyuktha, K.; Chinnala, K. M.; Prathiba, G.; Rajendhar, D. and Reddy, P. S. (2017):

Evaluation of anti-ulcer activity of ethanolic root extract of Beta vulgaris in rats. Int $\mathrm{J}$ Basic Clin Pharmacol., 6(2):359-364.

Scheiman, J. M.; Yeomans, N.D.; Talley,N.J,; Vakil,N.,Chan, F.K; Tulassay, Z.; Rainoldi, J.L.; Szczepanski, L.; Ung, K. A.; Kleczkowski,D.; Ahlbom, H.; Naesdal,J. and Hawkey,.(2006) :

Prevention of ulcers by esomeprazole in at-risk patients using non-selective NSAIDs and Cox-2 inhibitors.Am. J. Gastroenterology,101:701-710 
Egypt. J. of Nutrition and Health Vol. 14 No. 2 July (2019)

Seth, S. D. (2005):

Analgesic Antipyretic and Anti-Inflammatory Drugs In: Textbook of Pharmacology. Second Edition., New Delhi Churchill Livingstone, 1-6:170-171.

Shehata, M.S.M. and Soltan, S.A. (2013):

Effects of bioactive component of kiwi fruit and avocado (fruit and seed) on hypercholesterolemic rats. World Journal of Dairy \& Food Sciences, 8 (1): 82-93.

Snedecor, G. and Cochran, W. (1979):

Statistical Method. 6th Ed. Lowa State Collage U. S. A : 841.

Souza, M. H.; Mota, J. M.; Oliveira, R. B., and Cunha, F. Q. (2008):

Gastric damage induced by different doses of indomethacin in rats is variably affected by inhibiting iNOS or leucocyte infiltration. Inflamm. Res., 57:28-33.

Suleyman, H.; Albayrak, A.; Bilici, M. et al., (2010):

Different mechanisms in formation and prevention of indomethacin-induced gastric ulcers. Inflammation, 33:224-34.

Suleyman. B.; Mammadov, R.; Ozcicek, A.; Ozcicek, F.; Kuzucu, M.; Altuner, D. and Suleyman, Z. (2018):

Effect of benidipine on experimental gastric ulcers in rats. Medicine Science., doi: 10.5455/medscience.2018.07.8883.

Tahoon, N. A. and El Sheikh, N. A. (2016):

Effect Different Levels of Powder and Aqueous Extract of Artichoke Leaves on Gastric Ulcer. World Journal of Dairy \& Food Sciences 11 (2): 131-140.

Taiwo, V. O. and Anosa, V. O. (2000):

In vitro- erythrophagocytosis by cultured macrophages stimulated with extraneous substances and those isolated from the blood, spleen and bone marrow of Boran and N'dama cattle infected with trypanosoma congolense and t. vivax. Onderstepoort J. Vet. Res. 67, 273-287.

Targownik, L. E.; Metge, C. J.; Leung, S. and Chateau D. G. (2008):

The relative efficacies of gastroprotective strategies in chronic users of nonsteroidal antiinflammatory drugs. Gastroenterology, 134: 937-944.

Thaipong, K.; Boonprakob, U.; Crosby, K.; Cisneros-Zevallos, L. Byrne, H. D. (2006). Comparison of ABTS, DPPH, FRAP, and ORAC assays for estimating antioxidant activity from guava fruit extracts. Journal of Food Composition and Analysis, 19, 669-675.

The Nutritional requirements of laboratory animals (1995):

Fourth revised edition National Research Council.

Venter, A. (2013):

Phenolic composition and in vitro antioxidant capacity of South African plums (prunus salicina lindl). Stellenbosch University http://scholar.sun.ac.za,1-117. 
Wallace, J. L. (2008):

Prostaglandins, NSAIDs, and gastric mucosal protection: Why does not the stomach digest itself? Physiol. Rev., 88: 1547-1565.

Wallace, J. L., and Vong, L. (2008):

NSAID-induced gastrointestinal damage and the design of Gl-sparing NSAIDs. Curr. Opin. Investig. Drugs, 9: 1151-1156.

Wang, L.; Bordi, P.L.; Fleming, J.A.; Hill, A.M. and Kris-Etherton, P.M. (2015):

Effect of a moderate fat diet with and without avocados on lipoprotein particle number, size and subclasses in overweight and obese adults: A randomized, controlled trial. J. Am. Heart Assoc., 7;4(1):e001355.

\section{النشاط المضاد للقرحة لعصير الأفوكادو وعصير الكيوي على قرحة المعدة المحدثة}

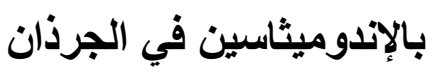

$$
\text { أمبرة لطفي عبل الرؤف عبد الله }
$$

قسم التغذية و علوم الأطعمة ـ كلية الاقتصاد المنزلي - جامعة الأزهر

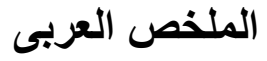

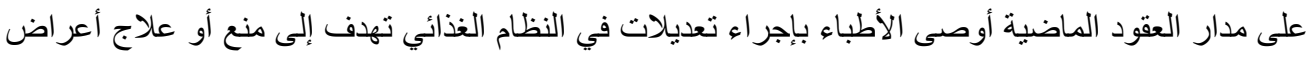

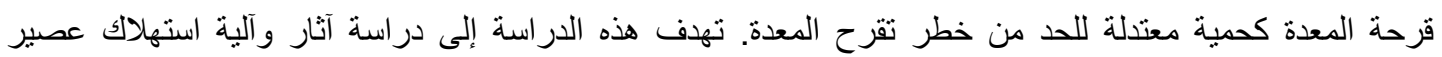
الأفوكادو وعصير الكيوي لتخفيف القرحة الهضمية في الجرذان. تم استخدام ستة وثلاثون من ذكور الجرذان البران البيضاء

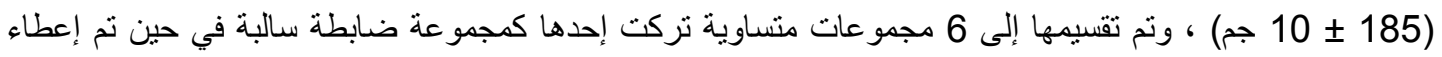

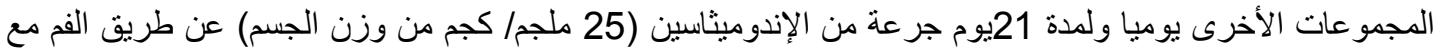

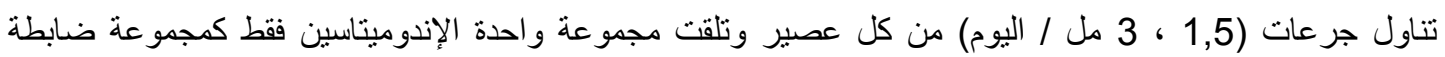

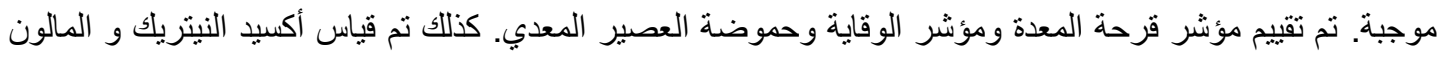

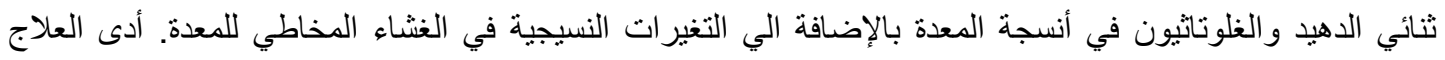

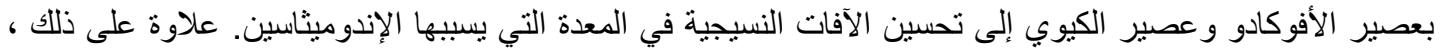

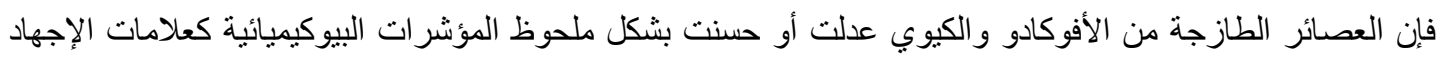
التأكسدي مثل المالون ثنائي الدهيد و أكسيد النيتريك و الإنزيمات المضادة للاككسة مثل الجلوتاثنيون ، و والتي تعطلت بشكل

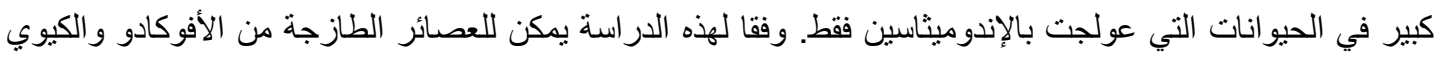
أن تحمي من القرحة الهضمية والآثار الجانبية الأخرى. وقد يكون هذا بسبب المحتوى العالي من مركبات الفينول و الفلافونويد في هذه العصائر.

الكلمات المفتاحية: قرحة المعدة - الإندوميثاسين ـ الأفوكادو - الكيوي ـ أكسيد النيتريك ـ الجلوناثيون 